\title{
Calculation Of Reinforced Concrete Slabs On Yielding Supports Under Short-term Dynamic Loading
}

\author{
Zaur Galyautdinov ${ }^{1, *}$ \\ ${ }^{1}$ Tomsk State University of Architecture and Building, 634003, г. Tomsk, 2 Solyanaya sq., Russia
}

\begin{abstract}
Buildings and structures used for industrial and civil purposes are exposed to dynamic impacts of emergency nature. To protection of structures one should improve methods for dynamic analysis of structures and also elaborate effective design solutions that ensure structural reliability under intensive dynamic impacts. The given paper considers the multi-layer deformation model for concrete beams; calculation method for 2-way reinforced concrete slabs was elaborated on its basis. In regards to structural solutions, application of yielding supports provides the increasing structural resistance towards dynamic loads of large intensity. The yielding supports are presented as deformable elements of ring crosssection which are characterized by three phases of deformation: elastic, elasto-plastic and hardening phase. The numerical study allowed to evaluate the influence of yielding supports stiffness in plastic phase of deformation on the work of reinforced concrete slabs, as well as the effect of the nature of stiffness distribution along the perimeter of the slab and the deformation level of yielding supports at the moment of transition to the plastic phase deformation. Resulting from the calculations physical and mechanical parameters of supports were defined allowing getting the maximum effect in decrease of the stress-strain state of the structure.
\end{abstract}

\section{Introduction}

The impact of single-acting dynamic loads of emergency nature on buildings and structures imposes special requirements for operation of these structures. Structures subjected to the influence of these loads, should primarily satisfy the strength requirement, i.e. the structure should remain integral after significant deformations and displacements. Considerable displacements of reinforced concrete structures under dynamic loads are accompanied by occurrence of plastic strain in concrete and rebar and concrete cracking.

Numerical calculation methods, the finite element method (FEM) in particular, provide wider functionality and allow taking into account the non-linear dynamic deformation of materials in low volume, limited by the size of the finite element. Application of FEM results in building the systems of linear algebraic equations of large dimension, which are

\footnotetext{
*Corresponding author: gazr@yandex.ru
} 
possible to solve only with the use of computers. However, development of computing and calculation methods allows us to solve such kinds of equations quickly and effectively.

Accuracy and reliability of the obtained results are fully determined by the models, describing behaviour of reinforced concrete under intensive dynamic loading. Application of linear and plane models for calculation of rod type and planar reinforced concrete elements does not allow considering the irregularity in the stress distribution along the height of the elements section. The multi-layer model of deformation of reinforced concrete beams which is used in static calculations does not possess the mentioned limitations [1, 3, $11,15,16]$. Splitting into layers along the height of the section allows to consider different levels of strain in the layers, and their switching off due to concrete cracking, as well as peculiar features of nonlinear deformation of concrete and rebar within a single layer.

Durability of structures under intensive dynamic impacts the active means of protection are being increasingly implemented, i.e. various kinds of seismic isolation bearings used under seismic impacts, vibration isolators, used under the action of dynamic loads of periodic nature, etc. Emergency dynamic loads refer to single-time loads and are characterized by low probability of occurrence; however buildings and structures, subject to specified impacts are designed to be able to fully withstand the mentioned emergency load. The use of active means of protection, such as yielding supports allows increasing the energy intensity of the system "yielding support - structure» and decrease the intensity of dynamic effects $[8,9,10,14]$. As a result, construction cost and labor intensity of their manufacture are reduced.

Experimental research of reinforced concrete beams [3, 5, 7] and 2-way reinforced concrete slabs $[3,4]$ on yielding supports testify high-efficiency of their use under intensive dynamic loading. The obtained data showed that the greatest effect can be achieved when the supports work in the plastic phase and the phase of hardening.

The given work presents a model of dynamic deformation of 2-way reinforced concrete slabs and provides the results of theoretical research of reinforced concrete slabs placed on yielding supports under short-term dynamic loading. The work of structure has been considered in elastic and elasto-plastic phases, while work of supports was studied in the plastic phase and the phase of hardening.

\section{Research methods}

The studies define the response of the dynamic system «slab-yielding supports» using FEM. The motion equation of the system in matrix form is presented in increments and has the following form

$$
\mathbf{M} \cdot \Delta \ddot{\mathbf{u}}+\mathbf{K} \cdot \Delta \mathbf{u}=\Delta \mathbf{p}
$$

where $\mathbf{K}, \mathbf{M}$ are stiffness matrixes and mass system on the $i$-th stage of calculation; $\Delta \mathbf{p}$ is the increment of load vector on the $i$-th stage of calculation; $\Delta \mathbf{u}, \Delta \ddot{\mathbf{u}}$ are increment vectors of displacements and acceleration on the $i$-th stage of calculation.

In the equation (1) mass matrix $\mathbf{M}$ that describes the inertial characteristics of the system remains constant during dynamic deformation due to invariability of the elements mass. Along with that, the stiffness matrix of system $\mathbf{K}$ is a variable value, which is conditioned by the change of stiffness characteristics of the system due to the nonlinearity of the deformation curve of concrete and reinforcement, occurrence and development of cracks in concrete both on the surface of the slab and along its thickness, as well as fragmentation of compressed concrete and transition to the descending deformation branch. Accounting of these factors is performed within a physical model of reinforced concrete deformation. 
The description of the mechanical condition of reinforced concrete beams during shortterm dynamic loading was performed using multi-layer model $[1,3,11,15,16]$. This model determines the resistance of the section on the whole, while peculiar features of nonlinear deformation of concrete and rebar are recorded within a single layer by dynamic deformation diagrams of materials. Also, it should be noted that the use of multi-layer model allows using of the well proven flat and rod finite elements in the calculation.

According to the accepted model the slab is conditionally divided according to its thickness into the layers of small thickness $h_{i}$ (fig. 1, $a$ ). The distribution of deformations along the cross-section height is accepted as linear, while the stresses along height are distributed non-linearly, and within the layer, they are accepted as constant. Further stressstrain state of the element of the slab is considered on the sites of main deformations thus enabling to work only with normal strain, while tangential deformations are not considered. Generalized physical correlation in the main axes of deformations $n$ and 1 take the following form

$$
\left\{\begin{array}{c}
\Delta M_{n} \\
\Delta M_{l} \\
\Delta M_{n l} \\
\Delta N_{n} \\
\Delta N_{l} \\
\Delta N_{n l}
\end{array}\right\}=\left[\begin{array}{cccccc}
D_{11}^{M} & D_{12}^{M} & D_{13}^{M} & D_{11}^{M N} & D_{12}^{M N} & D_{13}^{M N} \\
& D_{22}^{M} & D_{23}^{M} & D_{12}^{M N} & D_{22}^{M N} & D_{23}^{M N} \\
& & D_{33}^{M} & D_{13}^{M N} & D_{23}^{M N} & D_{33}^{M N} \\
& & & D_{11}^{N} & D_{12}^{N} & D_{13}^{N} \\
& & & & D_{22}^{N} & D_{23}^{N} \\
\text { sym } & \text { met } & \text { ri } & \text { cal } & & D_{33}^{N}
\end{array}\right\} \times\left\{\begin{array}{c}
\Delta \chi_{0 n} \\
\Delta \chi_{0 l} \\
2 \Delta \chi_{0 n l} \\
\Delta \varepsilon_{0 n} \\
\Delta \varepsilon_{0 l} \\
\Delta \gamma_{0 n l}
\end{array}\right\},
$$

where $D_{r k}^{M}=\sum_{i=1}^{n} d_{r k(i)} \cdot h_{i} \cdot z_{i}^{2} ; D_{r k}^{M N}=\sum_{i=1}^{n} d_{r k(i)} \cdot h_{i} \cdot z_{i} ; D_{r k}^{N}=\sum_{i=1}^{n} d_{r k(i)} \cdot h_{i} ; r, k=1,2,3$.

a)

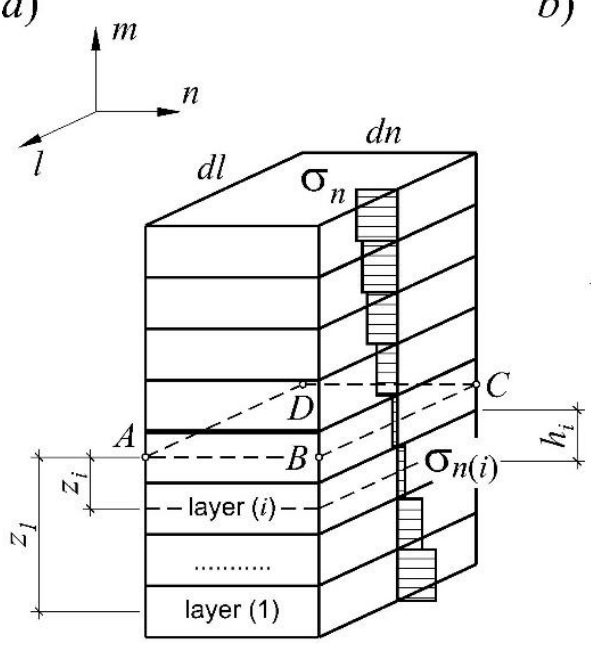

b)

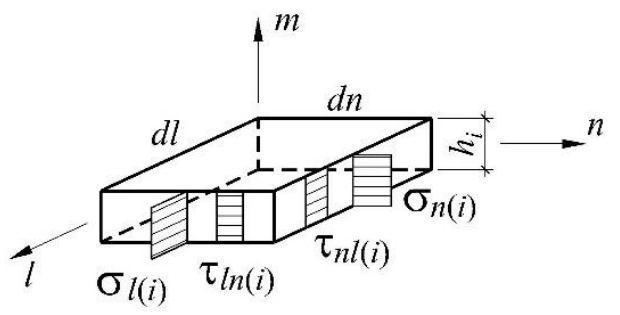

Fig. 1. The scheme of the stress state of the slab element in the main strain axes: $a$-element of the slab, conventionally divided into segments of small thickness; $b$ - stress state of a separate layer.

The elements $d_{r k(i)}$ represent elements of elasticity matrix of the separate layer. The influence of stress and strain in planes perpendicular to the median surface is disregarded, in each layer only stresses in XOY plane strain are valid (fig. 1, b), i.e., it is suggested that a 
separate layer is in the conditions of biaxial stress state. In general terms, the correlation between stress and strain increments is represented as

$$
\Delta \boldsymbol{\sigma}_{i}=\mathbf{D}_{s b, i} \cdot \Delta \boldsymbol{\varepsilon}_{i}
$$

where $\Delta \boldsymbol{\varepsilon}_{i}^{T}=\left\{\Delta \varepsilon_{n, i} \quad \Delta \varepsilon_{l, i} \quad \Delta \gamma_{n l, i}\right\}$ is vector of relative deformations increments for the $i$ th layer; $\Delta \boldsymbol{\sigma}_{i}^{T}=\left\{\Delta \sigma_{n, i} \quad \Delta \sigma_{l, i} \quad \Delta \tau_{n l, i}\right\}$ is vector stress increments; $\mathbf{D}_{s b, i}=\mathbf{D}_{b, i}+\mathbf{D}_{s, i}$ is tangential elasticity matrix of reinforced concrete; $\mathbf{D}_{b, i}$ is tangential elasticity matrix that takes into account the contribution of concrete in the overall stiffness of the element; $\mathbf{D}_{s, i}$ is tangential elasticity matrix that takes into account the contribution of reinforcement in the overall stiffness of the element.

Defining the elements of elasticity matrix of concrete $\mathbf{D}_{b, i}$ is based on the diagram of dynamic deformation of concrete, describing the behaviour of the material at the sites of main deformations. For concrete under compression and tension we accept parabolic dependence according to research [13], taking into account the downward branch, deformation velocity, and confinement reinforcement influence

$$
\sigma_{b}=R_{b d} \frac{\alpha_{1} x_{1}+\left(\alpha_{2}-1\right) x_{1}^{2}}{1+\left(\alpha_{1}-2\right) x_{1}+\alpha_{2} x_{1}^{2}}
$$

where $x_{1}=\frac{\varepsilon_{b}}{\varepsilon_{R 1}}$ is relative value of deformations; $R_{b d}$ is dynamic strength of concrete; $\alpha_{1}$ and $\alpha_{2}$ are the coefficients that reflect the influence of transverse reinforcement and deformation velocity on changes in the form of concrete diagram.

For reinforcing steel resistance diagram was accepted as a piecewise-linear approximation, reflecting its work in elastic and plastic phases and phase of hardening [6].

Due to the fact that within a layer biaxial stress state was accepted the estimation of dynamic strength of concrete is based on the criterion of durability $[2,17]$.

Based on the given model of reinforced concrete dynamic deformation the algorithm and calculation program for reinforced concrete structures were elaborated. The program is based on FEM, while approximation was performed by flat finite elements with five degrees of freedom in the node Z, UX, UY (fig. 2, a). Consideration of the supports flexibility was conducted using special finite elements; their longitudinal stiffness could be changed according to nonlinear law. These finite elements were placed in the nodes with flexible connection along the directions of degrees of freedom. During calculation the deformation diagram of yielding support was accepted as piecewise-linear (fig. 2,c) in accordance with the real deformation nature of the deformable elements [4].

Iterative calculation procedure (1) has been developed on the basis of Newmark- $\beta$ method. The calculation has been conducted with adjustment of the stiffness of each element at the next calculation stage by time. This has been performed by changing elasticity modulus of reinforcement and secant modulus of elasticity of concrete in accordance with the diagrams of $\sigma-\varepsilon$ and conditions of material work. Simultaneously, condition of yielding supports is controlled at each stage of calculation. In case of exceeding the ultimate strain of deformable elements corresponding to the definite stage transition to the next phase of support deformation takes place (elasto-plastic or hardening 
phase). It is accompanied by changing the stiffness parameters of yielding supports in the design scheme.

a)

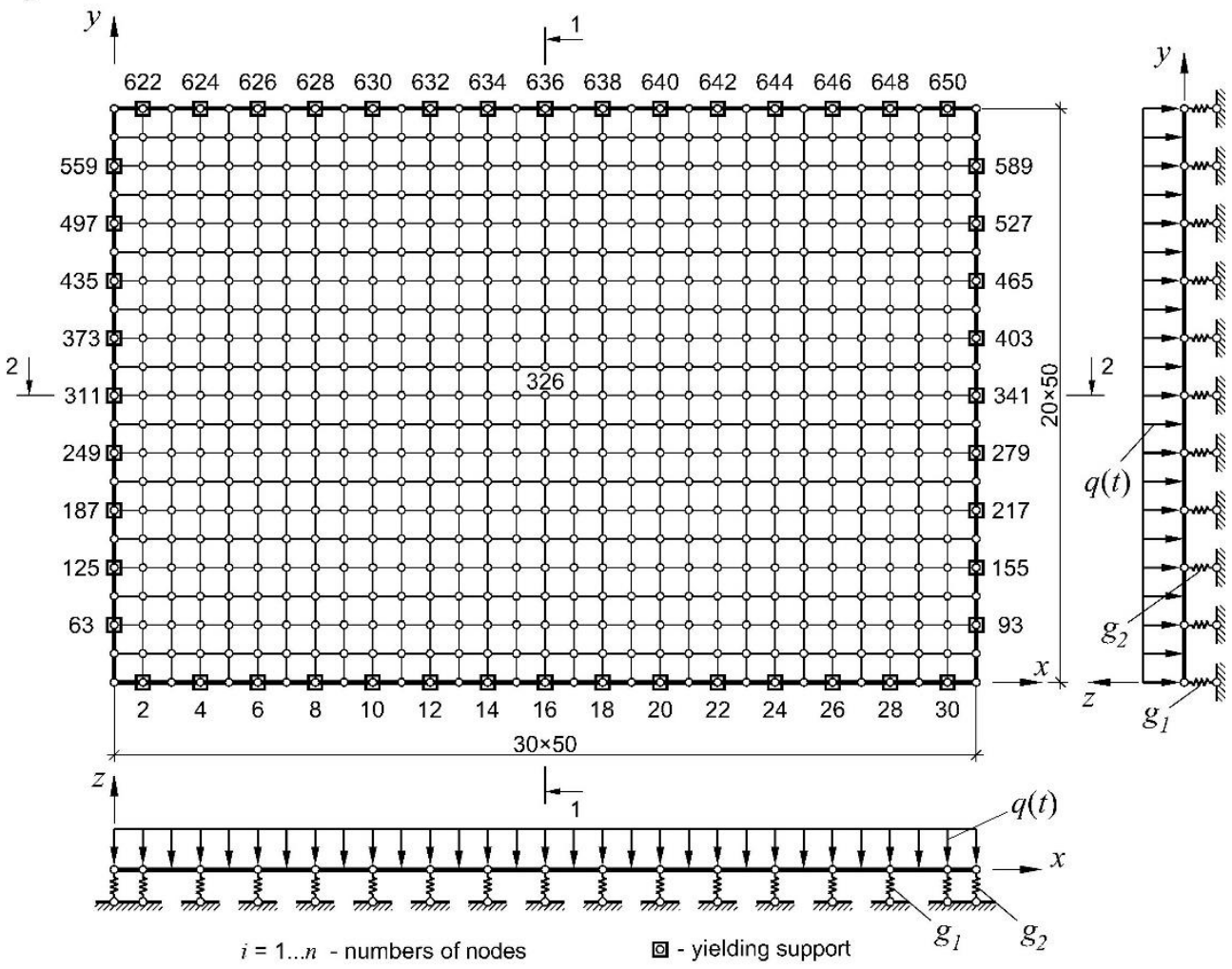

b)

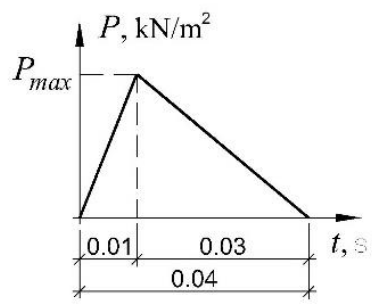

c)

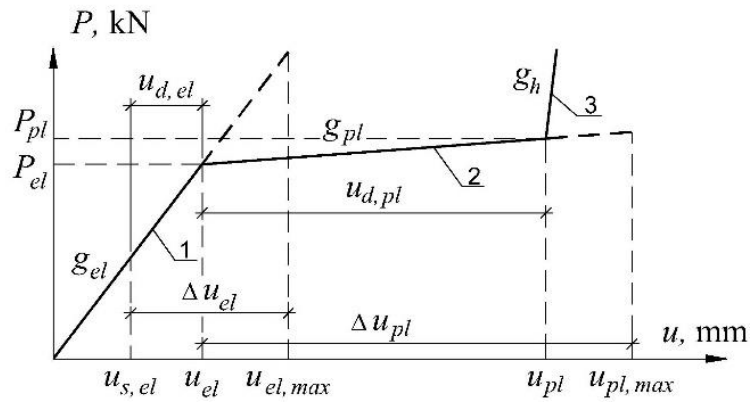

Fig. 2. Scheme of the slab division into finite elements $(a)$, law of variation of the load adopted in numerical calculations $(b)$ and deformation curve of yielding supports $(c)$ : 1 -elastic phase of support deformation; 2 - elasto-plastic phase of supports deformation; 3 -hardening phase.

In order to assess the validity of the presented model and calculation program comparative analysis of the calculation results and experimental data given in the work has been conducted [12]. The results were compared in regards to displacements and velocities for reinforced concrete slabs on rigid and yielding supports. Comparative results given in figs. 3, 4 and 5 demonstrate rather high accuracy of the suggested model of reinforced concrete dynamic deformation. 
a)

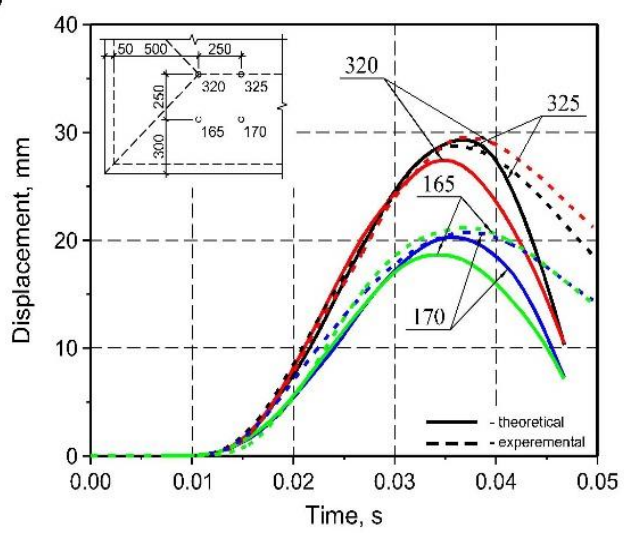

b)

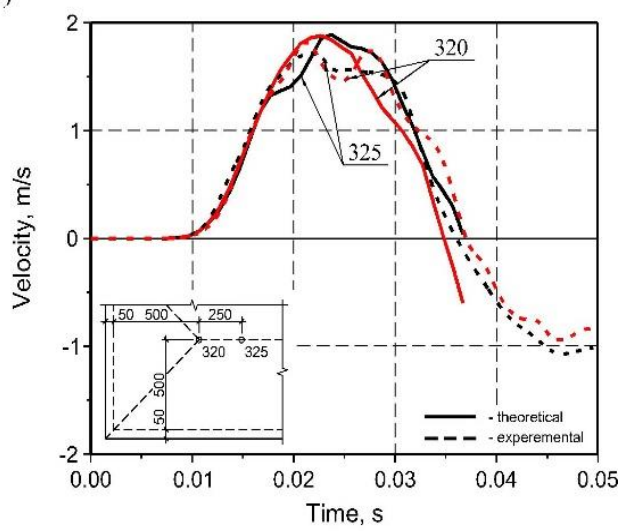

Fig. 3. Comparison of theoretical and experimental displacements $(a)$ and velocities $(b)$ of reinforced concrete slabs on rigid supports during their deformation in elasto-plastic phase.

a)

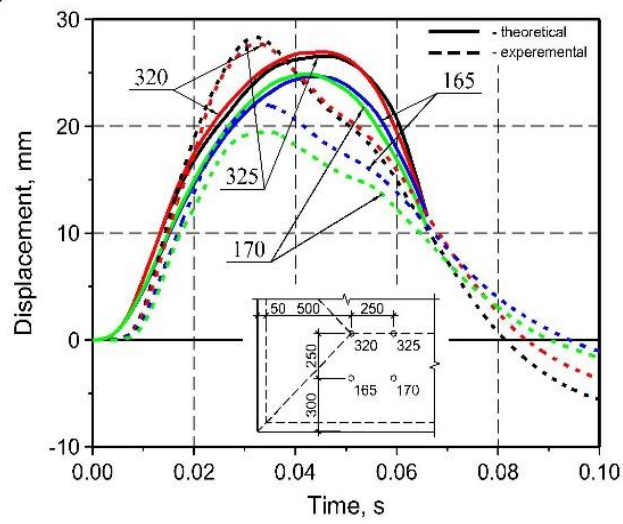

b)

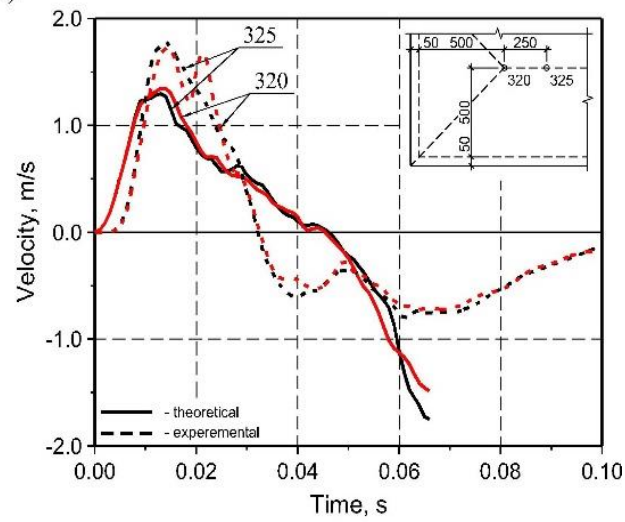

Fig. 4. Comparison of theoretical and experimental displacements $(a)$ and velocities $(b)$ of reinforced concrete slabs on elasto-plastic yielding supports.

a)

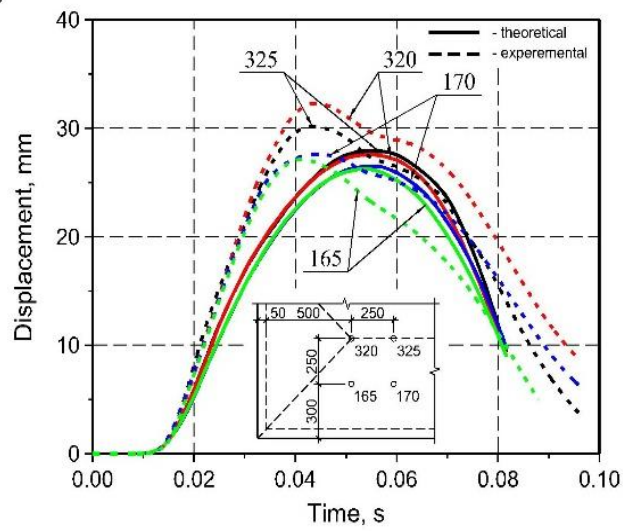

b)

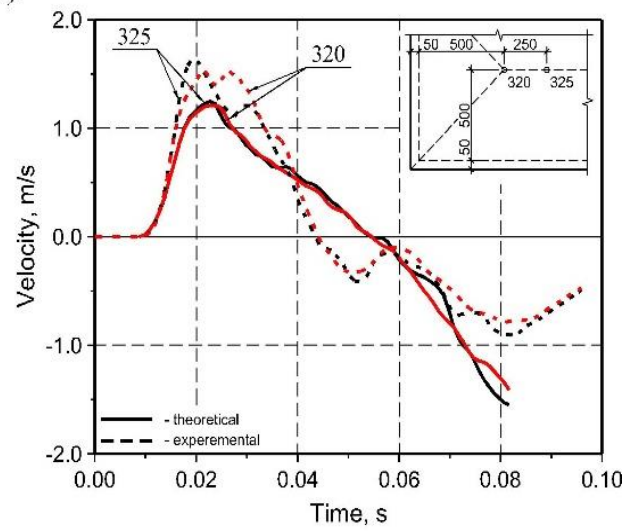

Fig. 5. Comparison of theoretical and experimental displacements $(a)$ and velocities $(b)$ of reinforced concrete slabs on yielding supports with hardening. 


\section{Results of numerical research}

The relative stiffness of yielding supports in the elastic phase of work has been varied in the limits of $g_{e l}=10000 \ldots 200000 \mathrm{kN} / \mathrm{m} / \mathrm{m}$. The stiffness of supports in plastic phase has assumed to be equal to $5 \%$ of the support stiffness in elastic stage, which corresponds to the results of experimental studies of yielding supports [3]. Quantitative evaluation of influence of supports flexibility has been performed on the displacements in the middle of a slab (node 326, fig. 2, a); two sections have been under study (1-1 and 2-2, fig. 2, a).

In the studies two variants of distribution of yielding supports stiffness along the perimeter of the slab have been considered $-g_{e l 1} / g_{e l 2}$ and nonlinear sinusoidal distribution of stiffness along the sides of the slab. Here $g_{e l 1}$ and $g_{e l 2}$ is the stiffness of yielding supports in the elastic phase along the long and short sides of the slab respectively.

Analysis of deformation of 2-way reinforced concrete slabs shows a significant influence of the stiffness of yielding supports on the stress-strain state of structures. In case of low supports stiffness their deformation under dynamic loading is significantly higher than deformations of the structure (fig. 6,a). Thus, energy absorption of external action mainly occurs due to deformation of yielding supports, wherein deformations of the structure are low. The oscillation period of the structure increases, displacements do not exceed deflections of slabs on rigid supports. Also, it should be noted that intensive development of slab displacements begins with some time-shift in regards to deformation of yielding supports.

a)

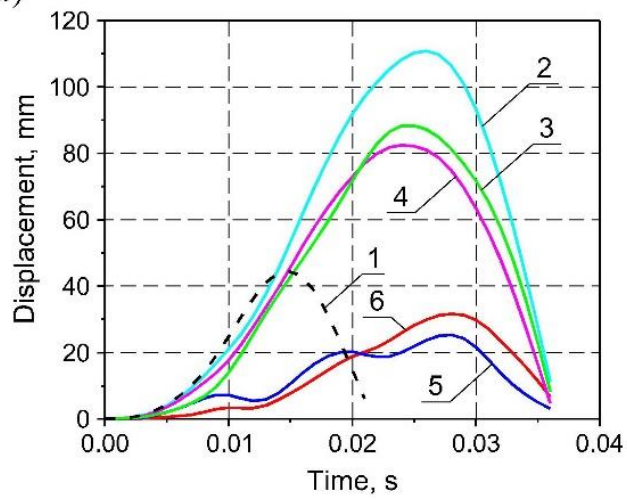

b)

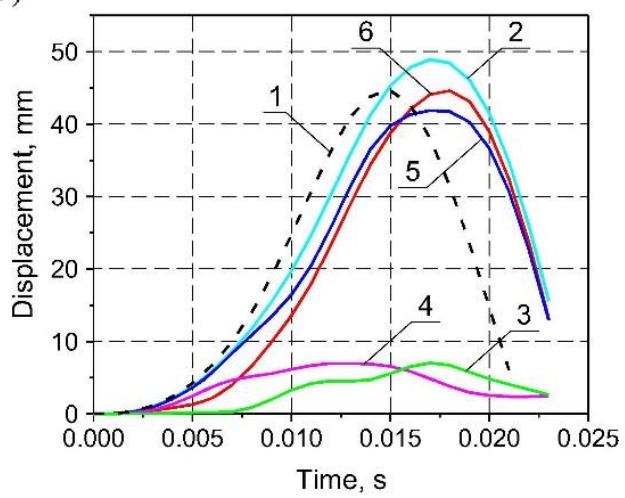

Fig. 6. Change of displacements of reinforced concrete slabs on rigid and yielding supports deformed in elasto-plastic phase over time $\left(g_{e l 1} / g_{e l 2}=4\right): a$ - for $g_{e l 1}=10000 \mathrm{kN} / \mathrm{m} / \mathrm{m} ; b$ - for

$g_{e l 1}=200000 \mathrm{kN} / \mathrm{m} / \mathrm{m} ; 1-$ displacements in the center of the slab on rigid supports; 2 - full displacements in the center of the slab on yielding supports; 3 - displacement of support (node 16 fig. 2,a); 4 - displacement of support (node 311 fig. 2,a); 5 -maximum displacement of the slab in section 1-1 without considering deformation of supports; 6 - maximum displacement of the slab in section 2-2 without considering deformation of supports.

When stiffness of yielding supports increases the redistribution between deformations of supports and structure takes place. Displacements of slabs on yielding supports of larger stiffness are much bigger than deformations of supports (fig. 6, $b$ ). Deformation of structure and supports begins almost simultaneously, the oscillation period and displacements of structure on flexible and rigid supports are close.

During the transition of supports to the hardening stagephase, one can observe some special features in deformation of structures. Yielding supports absorb part of dynamic 
impact energy. Transition of supports to the hardening phase leads to their switching off. As a result, the energy of external influence which is absorbed by yielding supports is fully redistributed to the slab. This results in a sharp growth of displacements of the slab (fig. 7). The value of displacement incrementation is determined by the stiffness of yielding supports. Yielding supports of low rigidity $\left(g_{e l 1}=10000 \mathrm{kN} / \mathrm{m} / \mathrm{m}\right)$ perceive the main part of energy of dynamic loading (fig. 6, a). This is why during by hardening of the slabs some part of energy which has not been absorbed by supports goes to the structure. This leads to a significant growth of deflections of the slab (fig. 7,a). With the increase of stiffness of supports the value of energy absorbed by supports decreases so that the increment value of displacement also decreases (fig. 7, $b$ ).

a)

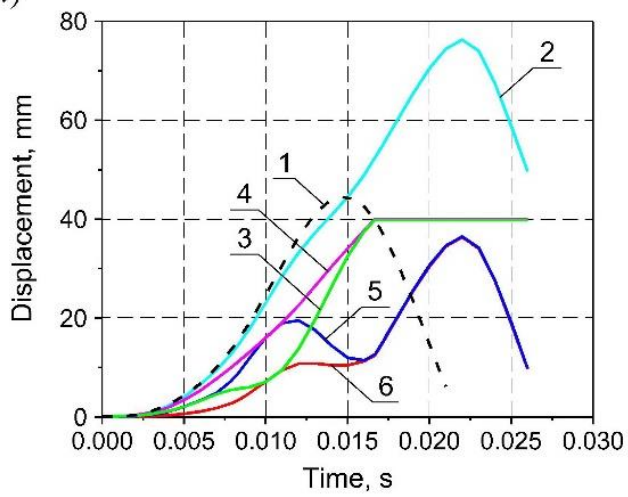

b)

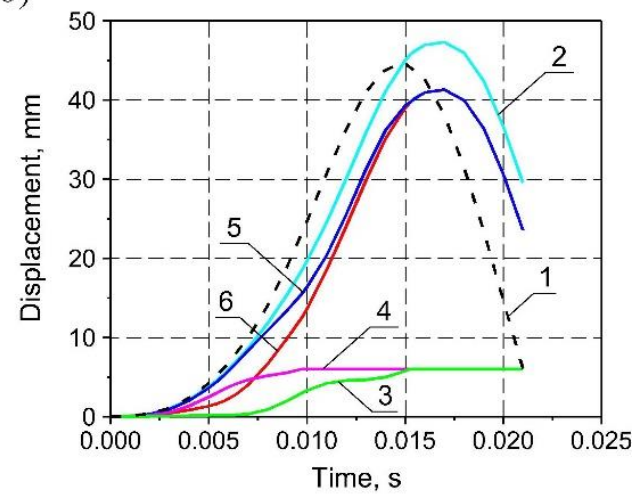

Fig. 7. Change of displacements of reinforced concrete slabs on rigid and yielding supports deformed in in elasto-plastic phase with transition to the hardening phase $\left(g_{e l 1} / g_{e l 2}=4\right): a$-for

$g_{e l 1}=10000 \mathrm{kN} / \mathrm{m} / \mathrm{m} ; b-$ for $g_{e l 1}=200000 \mathrm{kN} / \mathrm{m} / \mathrm{m} ; 1$ - displacements in the center of the slab on rigid supports; 2 - full displacements in the center of the slab on yielding supports; 3 -displacement of support (node 16 fig. 2, $a$ ); 4 - displacement of support (node 311 fig. 2, $a$ ); 5 -maximum displacement of the slab in section 1-1 without considering deformation of supports; 6 - maximum displacement of the slab in section 2-2 without considering deformation of supports.

In addition, it should also be noted that under the dynamic influence structures with less stiffness of supports have greater velocity at the moment of the transition to the phase of hardening, i.e. the value of inertial loads during deceleration of structure will be higher. The displacement velocity of supports (node 16 fig. 2,a) is obtained from the calculation results: at $g_{e l 1}=10000 \mathrm{kN} / \mathrm{m} / \mathrm{m}-3.5 \mathrm{~m} / \mathrm{s}$, at $g_{e l 1}=200000 \mathrm{kN} / \mathrm{m} / \mathrm{m}-0.8 \mathrm{~m} / \mathrm{s}$.

The influence of stiffness distribution of yielding supports along the perimeter of the slab and working phases of support (elasto-plastic and hardening) are shown in fig. 8 . During deformation of supports in elasto-plastic phase without transition to the hardening phase, the decrease of slab displacements can be over $50 \%$. Wherein, the most effective case is when $g_{e l 1} / g_{e l 2}=4$, where one can observe reduction of slab displacements throughout the range of the investigated rigidities of yielding supports. In case of nonlinear stiffness distribution of supports positive effect is observed only at low values of supports stiffness

\section{$\left(g_{e l 1} \leq 50000 \mathrm{kN} / \mathrm{m} / \mathrm{m}\right)$.}

Transition to the hardening phase for slabs being deformed in elasto-plastic phase with nonlinear stiffness distribution of supports along the perimeter leads to increase of the maximum deflection of structure compared to the slabs where supports are deformed in elasto-plastic phasee. At $g_{e l 1} / g_{e l 2}=4$ and stiffness value $g_{e l 1}=50000 \mathrm{kN} / \mathrm{m} / \mathrm{m}$ yielding 
supports transition to the phase of hardening leads to the decrease of maximal displacements value, i.e. greater positive effect is observed compared to elasto-plastic straining of supports. The influence of supports transition to the phase of hardening on maximum displacement by sections $1-1$ and 2-2 is almost equal irrespective of the distribution nature of yielding supports stiffness along the perimeter of the slab.

a)

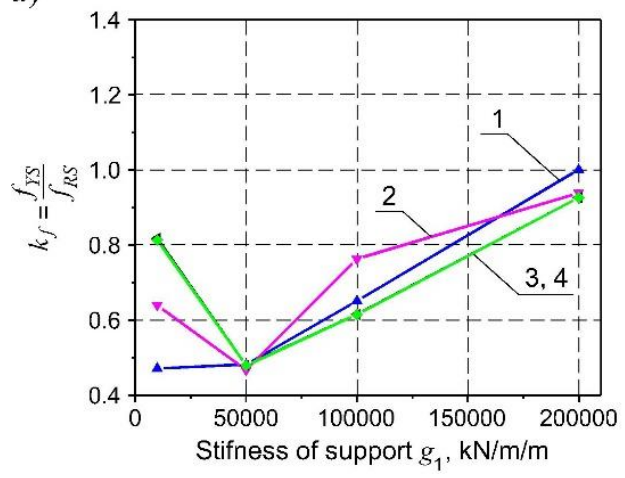

b)

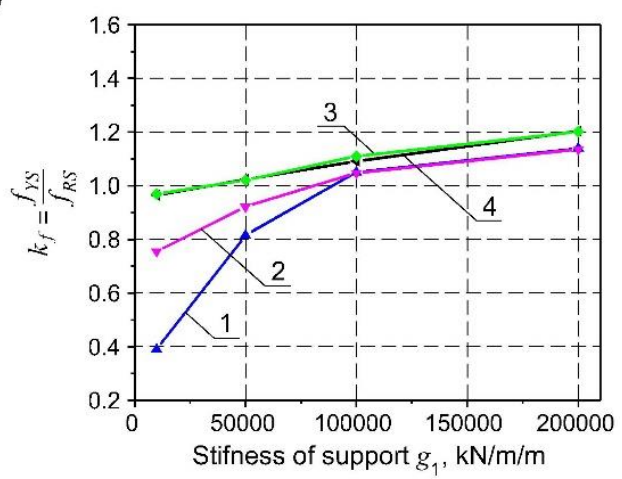

Fig. 8. Influence of supports flexibility on maximum deflection of the slab at $g_{e l 1} / g_{e l 2}=4(a)$ and nonlinear stiffness distribution of supports $(b): 1-$ in section 2-2 at elasto-plastic supports straining 2 - in section 1-1 at elasto-plastic supports straining; 3 - in section 2-2 at elasto-plastic supports straining with transition to the stage of hardening; 4 - in section 1-1 at elasto-plastic supports straining with transition to the stage of hardening.

The calculations have also demonstrated that deformations of the structure are determined by the level of elastic displacements of supports $u_{e l}$. After reaching this level the transition of support to plastic deformation stage occurs. Fig. 2, $c$ presents the scheme of deformation of yielding supports. Under the static design load yielding support gets the displacement $u_{s, e l}$. As the result of emergency dynamic influence support receives an additional increment of displacements $u_{d, e l}$. After that yielding support transforms to the plastic deformation phase. The total support displacements in elastic stage does not exceed the limit value $u_{s, e l}+u_{d, e l}<u_{e l, \max }$, where $u_{e l, \max }$ - maximum elastic deformations of yielding support, if it deforms only in elastic stage, for a given law of load changes over time. Acceptable interval of flexible displacements of support under dynamic impact is $\Delta u_{e l}<u_{e l, \max }-u_{s, e l}$.

The obtained results show that the greatest reduction of displacements has been achieved when $0.4 \Delta u_{e l}<u_{e l}<0.8 \Delta u_{e l}$ (fig. 9). With bigger or lesser value the effectiveness of yielding supports considerably reduces or even turns negative. The effectiveness of yielding supports decreases with the increase of support stiffness and does not depend on the nature of stiffness distribution.

Another important parameter in the assessment of influence of supports flexibility on structural deformations is possibility of supports transition to the hardening phase. In case yielding supports face hardening stage under dynamic impact, stress-strain state of the structure depends on the value of yielding supports deformations $u_{p l}$ (fig. 2, c), when support is switched off.

Fig. 10 shows dependencies which describe the maximum displacements of the slab with different levels of deformation of yielding supports at the transition to hardening phase $u_{p l}$. According to diagrams in almost all cases the maximum effect is observed at a later 
supports transition to hardening phase, i.e. the higher is $u_{p l}<u_{p l, \max }$, max the lower the maximum deflection of the slab is. Here $u_{p l, \max }$ are maximum plastic deformations of yielding supports in the absence of transition to the phase of hardening

a)

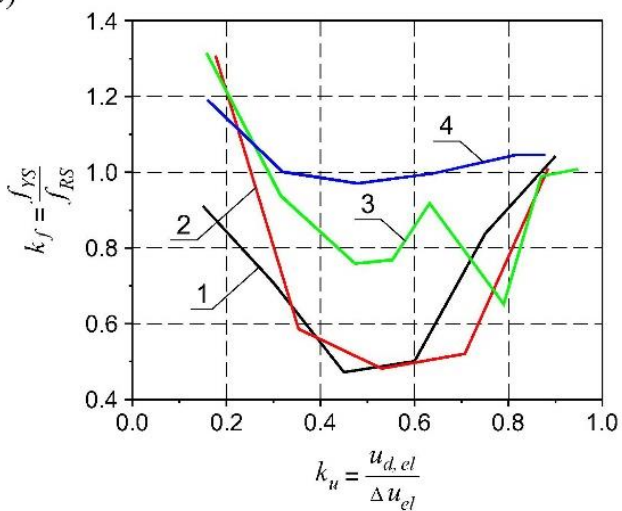

c)

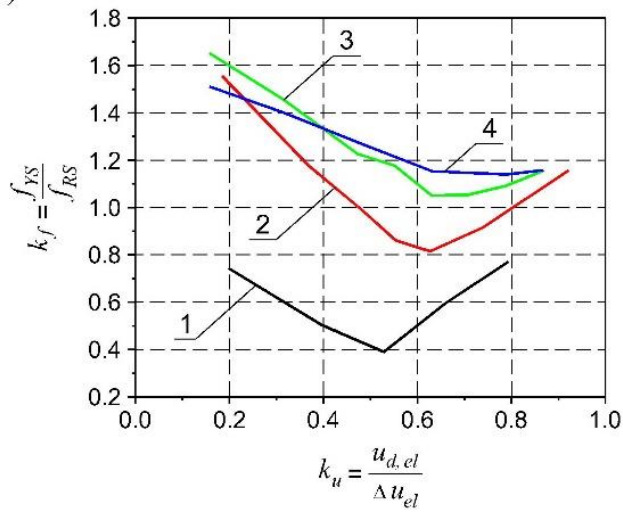

b)

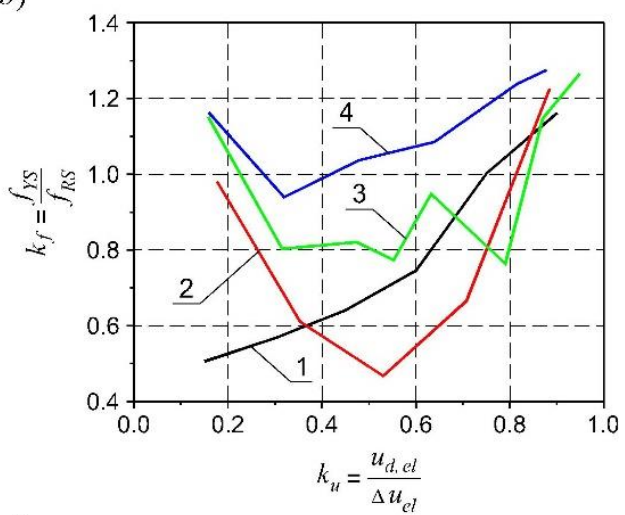

d)

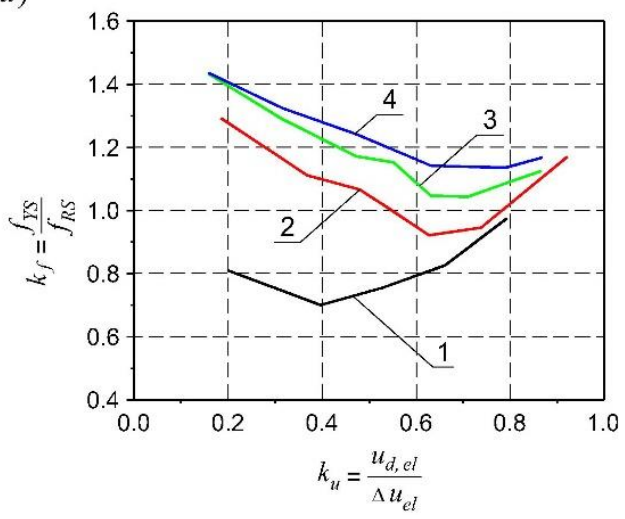

Fig. 9. Influence of value of supports displacements at transition to plastic phase on slab displacements: $a$-in section $2-2$ at $g_{e l 1} / g_{e l 2}=4 ; b$-in section $1-1$ at $g_{e l 1} / g_{e l 2}=4 ; c-$ in section 2-2 with nonlinear stiffness distribution of supports on the sides of the slab; $d$-in section 1-1 with nonlinear stiffness distribution of supports on the sides of the slab; 1 - for $g_{e l 1}=10000 \mathrm{kN} / \mathrm{m} / \mathrm{m} ; 2-$ for $g_{e l 1}=50000 \mathrm{kN} / \mathrm{m} / \mathrm{m} ; 3-$ for $g_{e l 1}=100000 \mathrm{kN} / \mathrm{m} / \mathrm{m} ; 4-$ for $g_{e l 1}=200000 \mathrm{kN} / \mathrm{m} / \mathrm{m}$.

However, it should be noted, that in case $g_{e l 1} / g_{e l 2}=4$ with $g_{e l 1}=100000 \mathrm{kN} / \mathrm{m} / \mathrm{m}$ one can observe an inverse relation.

For slabs with nonlinear distribution of flexibilities along the perimeter with increase of supports stiffness one can see that the influence of the moment of their transition to the phase of hardening becomes less, and with $g_{e l 1}=200000 \mathrm{kN} / \mathrm{m} / \mathrm{m}$ displacements do not depend on $u_{p l}$ (fig. 10, $c, d$ ).

\section{Results of numerical research}

The suggested multi-layer model of non-linear deformation of reinforced concrete enables to accurately assess the response of 2-way reinforced concrete slabs on rigid and yielding supports. Conducted numerical studies evaluated the efficiency of yielding supports 
application depending on the correlation of stiffness of the structure and yielding supports, their deformation stage, the nature of stiffness distribution of supports along the perimeter of the slab and the deformation level of yielding supports at the moment of transition to the phase of plastic deformation and to the hardening phase. The greatest effect in reduction of the stress-strain state parameters was achieved in the slabs with the following stiffness distribution of yielding supports: $g_{e l 1} / g_{e l 2}=4$.

a)

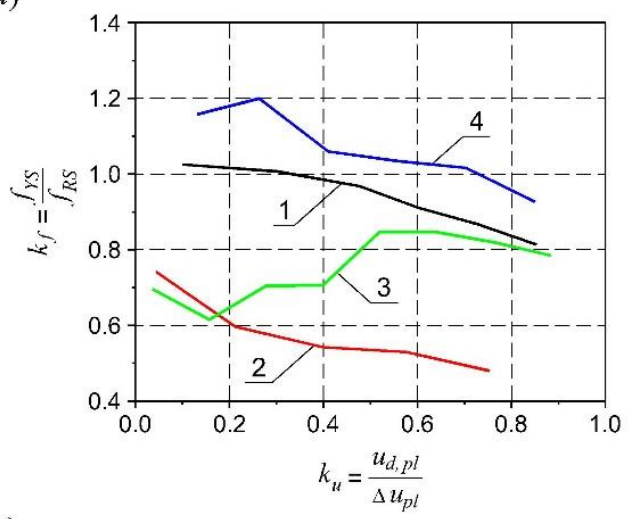

c)

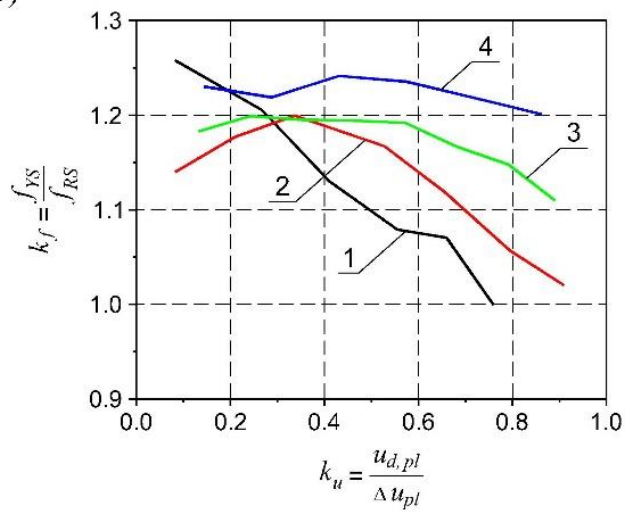

b)

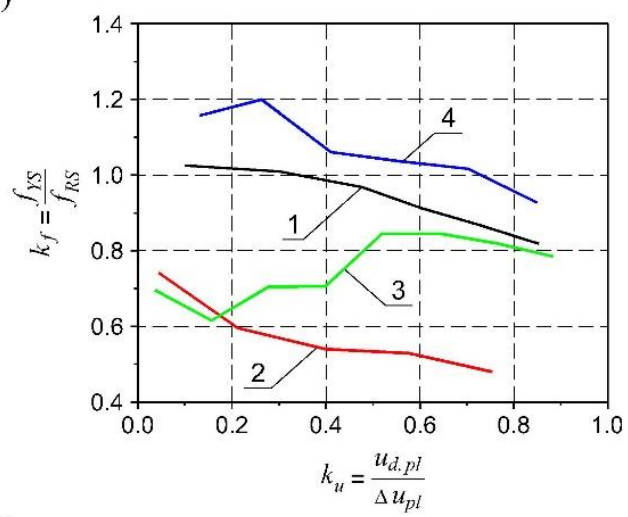

d)

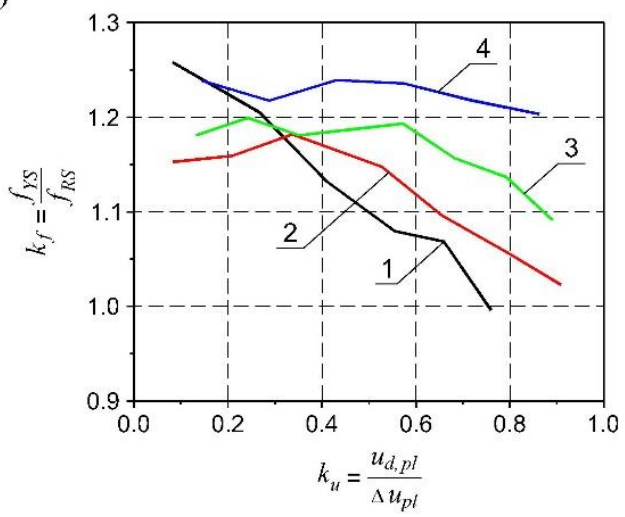

Fig. 10. Influence of value of supports displacements at transition to the phase of hardening on slab displacements: $a$-in section $2-2$ at $g_{e l 1} / g_{e l 2}=4 ; b$-in section $1-1$ at $g_{e l 1} / g_{e l 2}=4 ; c$-in section $2-2$ with nonlinear stiffness distribution of supports on the sides of the slab; $d$-in section $1-1$ with nonlinear stiffness distribution of supports on the sides of the slab; 1 - for $g_{e l 1}=10000 \mathrm{kN} / \mathrm{m} / \mathrm{m} ; 2$ for $g_{e l 1}=50000 \mathrm{kN} / \mathrm{m} / \mathrm{m} ; 3-$ for $g_{e l 1}=100000 \mathrm{kN} / \mathrm{m} / \mathrm{m} ; 4-$ for $g_{e l 1}=200000 \mathrm{kN} / \mathrm{m} / \mathrm{m}$.

The obtained results made possible to establish some general requirements to the physical and mechanical parameters of yielding supports. First, elastic deformation of yielding supports under dynamic deformation should fall within the range of $0.4 \Delta u_{e l}<u_{e l}<0.8 \Delta u_{e l}$. Second, supports should be designed without possibility of their transition into the hardening phase. In case this condition is impossible to integrate, the transition to the hardening phase is to be provided by the largest value of $\frac{u_{d, p l}}{\Delta u_{p l}}$. 


\section{References}

1. N. Karpenko, Novye exp. issled. i metody rasch. z/b konstr., 73-94 (1989)

2. O. Kumpyak, Z. Galyaudinov, D. Kokorin, Prochnost $i$ defomativnost zhelezobetonnykh konstruktsii na podatlivykh oporakh pri kratkovremennom dynamicheskom nagruzhenii, (Publishing Office of TSUAB, Tomsk, 2016)

3. O. Kumpyak, Z. Galyaudinov, D. Kokorin, V. Maksimov, Bet. i z/b - vzglyad v buduschee, 1, 315-325 (2014)

4. O. Kumpyak, Z. Galyaudinov, V. Maksimov, Bet. i zhelezobeton, 5, 16-19 (2014)

5. O. Kumpyak, D. Kokorin, Vestnik TSUAB, 1, 116-129 (2011)

6. O. Kumpyak, D. Kopanitsa, Prochnost $i$ deformativnost zhelezobetonnykh sooruzhenii pri kratkovemennom dinamiheskom nagruzhenii (STT, Tomsk, 2002)

7. O. Kumpyak, A. Malinovkii, A. Pedikov, Vestnik TSUAB, 2, 110-114 (2006)

8. B. Rastorguev, Stroit. mekh. i rasch. soor., 1, 50-57 (2009)

9. B. Rastorguev, Prochost zhelezobetonnykh konstruktsii zdanii vzryvoopasnykh proizvodstv $i$ spetsialnykh soruzhenii, podverzhennykh kratkovremennym dinamicheskim vozdeistviyam (Publishing Office of MSUCE, Moscow, 1987)

10. A.-R. Said, Povyshenie nesuschei sposobnosti zhelezobetonnykh konstruktsii pri vzryvnykh vozdeistviyakh (Publishing Office of MSUCE, Moscow, 1995)

11. F. Barrales, Development of a nonlinear quadrilateral layered membrane element with drilling degrees of freedom and a nonlinear quadrilateral thin flat layered shell element for the modeling of reinforced concrete walls (University of Southern California, 2012)

12. B. Chiaia, O. Kumpyak, L. Placidi, V. Maksimov, Eng. Struct., 96, 88-99 (2015)

13. W. Dilger, R. Koch, R. Kowalczyk, J. of the ACI, 81, 73-81 (1984)

14. F. Elfetori, Industr. Sc. and Eng., 7, 10-15 (2013)

15. F. Fujii, Beton und Stahlbetonbau, 74, 189-195 (1979)

16. D. Yan, G. Lin, Magazine of Concrete Research, 59, 45-52 (2007) 